\title{
A CLINICAL EVALUATION OF PYRIDOSTIGMIN BROMIDE IN THE REVERSAL OF CURARIZATION
}

\author{
Alexander W. Gotta, M.D., and Colleen A. Sullivan, M.B., Ch.B. ${ }^{\circ}$
}

THE ABILITY of pyridostigmin bromide, a chemical analog of neostigmine, to inhibit acetyl cholinesterase and to effect a reversal of the paralysing effect of $d$ tubocurarine has been known for some time.1,2 Although an early evaluation was critical of its use, ${ }^{3}$ a later study has indicated an anti-curare effectiveness equal to that of neostigmine, coupled with a longer duration of action, yet without the disadvantageous muscarinic side effects limiting the utility of neostigmine. ${ }^{4}$ The drug has also been found a useful antagonist to the relaxant effect of gallamine triethiodide. ${ }^{5}$

This study was undertaken to evaluate pyridostigmin bromide as an antagonist to curare during the administration of several commonly-used inhalation anaesthetic agents and in the circumstances usually found by the practising anaesthesiologist in the operating room.

\section{Method}

Sixty-one consecutive adult patients ( 58 female, 3 male) undergoing anaesthesia and surgery requiring the use of muscle relaxants were selected for the study. Patients with heart disease and/or pre-existing cardiac arrhythmias were excluded. No attempts were made to exclude patients with respiratory disease (Table I). The patients were premedicated with secobarbital sodium (100-150 $\mathrm{mg}$ ), and atropine sulphate $(0.4-0.8 \mathrm{mg})$ intramuscularly, approximately one hour prior to induction of anaesthesia.

TABLE I

Operative Procedures

\begin{tabular}{lr}
\hline \hline Abdominal hysterectomy & 34 \\
Cholecystectomy & $\mathbf{7}$ \\
Ovarian cystectomy & 6 \\
Salpingo-oophorectomy & $\mathbf{3}$ \\
Lysis of adhesions & 2 \\
Colostomy & $\mathbf{2}$ \\
Incisional herniorrhaphy & $\mathbf{2}$ \\
Marshall-Marchetti procedure & $\mathbf{1}$ \\
Myomectomy & $\mathbf{1}$ \\
Closure of colostomy & $\mathbf{1}$ \\
Appendectomy & $\mathbf{1}$ \\
Umbilical herniorrhaphy & $\mathbf{1}$ \\
\hline
\end{tabular}

Just before induction the tidal volume was determined, using a close-fitting anaesthesia mask and a Wright respirometer. Thiopental sodium was then ad-

'Department of Anesthesiology, St. Mary's Hospital, Catholic Medical Center of Brooklyn and Queens, Inc. 
ministered intravenously until there was a loss of eyelid reflex and/or loss of response to calling by name. Inhalation anaesthesia was administered until there was no response to painful stimulation (Table II). A peripheral nerve stimulator (Block-Aid Monitor) was then attached with needle electrodes over the ulnar nerve at the elbow and wrist, and the response to single stimulation, tetany, and the presence or absence of post-tetanic facilitation was noted. Base line tetany was assigned a value of $4+$, and diminished tetanic responses were graded on a scale down to 1 . Endotracheal intubation was effected after the intravenous administration of succinylcholine chloride $(40-60 \mathrm{mg})$, and inhalation anaesthesia was continued.

TABLE II

ANAESTHETIC AGENTS

\begin{tabular}{lr}
\hline Cyclopropane & 26 \\
Methoxyflurane & 20 \\
Diethyl ether & 10 \\
Halothane & 4 \\
Nitrous oxide & 1 \\
\hline
\end{tabular}

Throughout the operative procedure an attempt was made to maintain the patients in "light anaesthesia," i.e. analogous to plane I, stage III of Guedel's classification. After the responses to ulnar nerve stimulation had returned to normal, d-tubocurarine was administered, initially as a $3 \mathrm{mg}$ test dose, then in amounts necessary to produce a relaxed abdomen compatible with the performance of surgery. Further doses of curare were added as needed to maintain adequate relaxation.

The response to nerve stimulation was monitored at frequent intervals, as were the blood pressure and pulse. Lead 2 of the electrocardiogram was monitored continuously. After closure of the peritoneum, the pharynx and trachea were cleared of secretions, and pyridostigmin bromide $(10 \mathrm{mg}$ ) was administered intravenously, with careful observation of vital signs, electrocardiogram, tidal volume, and particularly changes in response to nerve stimulation.

The ability to maintain a well sustained response to a tetanizing current was taken as the end-point indicator of the complete reversal of curare effect. ${ }^{4}$ Pharyngeal and tracheal secretions were aspirated frequently and graded as light, moderate, moderately heavy, and heavy. Initially, atropine was not administered with the pyridostigmin. However, because of the high incidence of heavy secretions, atropine later was added in doses of 0.5 or $1.0 \mathrm{mg}$, immediately following the pyridostigmin. In order to obviate the development of severe arrhythmias, atropine was not administered in doses greater than $0.5 \mathrm{mg}$ when cyclopropane anaesthesia had been used. ${ }^{6}$ If tetany was not well sustained after 15 minutes, an additional $10 \mathrm{mg}$ of pyridostigmin was used, this time without atropine. Another $10 \mathrm{mg}$ of the drug was added again after 15 minutes, if necessary. All patients were monitored until the tetanic response was well maintained. 


\section{RESULTS}

Pyridostigmin bromide reversed the relaxant effect of d-tubocurarine in all 61 cases. Ten milligrams of the drug were sufficient in 49 patients, and 20 milligrams in 11. One patient required 30 milligrams. The mean duration of cyclopropane anaesthesia was 101 minutes; of ether, 131 minutes; of methoxyflurane, 124 minutes; of halothane, 96 minutes; and of nitrous oxide, 90 minutes. No attempt was made to administer curare on a dose-per-unit-weight basis, since studies have indicated this technique to be inadequate and misleading. ${ }^{7-9}$

Surprisingly, the amount of curare used did not vary markedly with the anaesthetic agent (Table III). However, the mean time for the reversal of curare varied markedly from a low of 3 minutes for both halothane and nitrous oxide to a high of 28 minutes for diethyl ether, with a overall mean time of 12 minutes (Table IV). This time for reversal during ether anaesthesia is significantly different from the overall mean. Excluding the longest reaction time of 93 minutes, the average for diethyl ether is still significantly different at 21 minutes. The anaesthetic agents thus fell into two groups on the basis of pyridostigmin reversal of curare, the "quick-reacting group" of cyclopropane, methoxyflurane, halothane, and nitrous oxide, and the "slow-reacting agent" diethyl ether. The reversal times were significantly low during halothane and nitrous oxide anaesthesia. However, the samples are so small as to be of questionable statistical validity.

No atropine sulphate was administered in 12 patients; $0.5 \mathrm{mg}$ were administered in 24 , and $1.0 \mathrm{mg}$ in 21 . If significant alterations in heart rate are arbitrarily

TABLE III

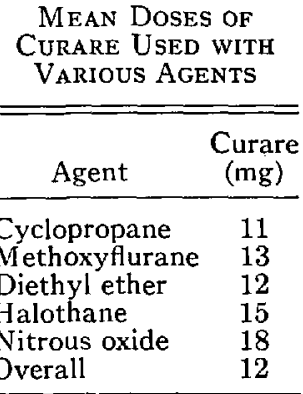

TABLE IV

Mean Time for Reversal of Curare

\begin{tabular}{lrc}
\hline \multicolumn{1}{c}{ Agent } & $\begin{array}{c}\text { Reversal } \\
\text { time } \\
\text { (min) }\end{array}$ & $\begin{array}{c}\text { Range } \\
\text { (min) }\end{array}$ \\
\hline Cyclopropane & 8 & $1-22$ \\
Methoxyflurane & 11 & $2-30$ \\
Diethyl ether & 28 & $5-93$ \\
Halothane & 3 & $2-5$ \\
Nitrous oxide & 3 & \\
Overall & 12 & \\
\hline
\end{tabular}


defined as a change of 10 per cent or more within 15 minutes after administration of the $\operatorname{drug}(s)$, then the use of pyridostigmin without atropine, in the presence of cyclopropane, produced a bradycardia in nine of twelve patients, and in all four patients receiving methoxyflurane. No other combination regularly produced bradycardia, the addition of $0.5 \mathrm{mg}$ of atropine producing tachycardia in 11 of 14 during cyclopropane anaesthesia. The use of $1.0 \mathrm{mg}$ of atropine produced tachycardia in seven of eight ether patients and in eight of thirteen methoxyflurane patients. These changes in rhythm were transient and not associated with changes in other vital signs.

Five patients developed marked bradycardia - i.e. a pulse rate less than 60 . None of the five had received atropine with the pyridostigmin. In three of the five, bradycardia of such severity resulted as to warrant subsequent intravenous administration of small amounts $(0.2 \mathrm{mg})$ of atropine for correction. In one patient two doses of $0.2 \mathrm{mg}$ each were necessary. Three of the five patients developed sinus bradycardia and two A-v dissociation with bradycardia. One sinus bradycardia reverted spontaneously to normal sinus rhythm, as did one A-v dissociation. All five arrhythmias occurred in patients receiving cyclopropane (Table V). All serious bradycardias occurred within ten minutes of administration of pyridostigmin and in no instance was there an associated hypotension. The arrhythmias treated with atropine responded promptly.

TABLE $V$

ARRHYTHMIAS

\begin{tabular}{|c|c|c|c|c|}
\hline $\begin{array}{l}\text { Anaesthetic } \\
\text { agent }\end{array}$ & Arrhythmia & $\begin{array}{l}\text { Pulse } \\
\text { change }\end{array}$ & Treatment & $\begin{array}{l}\text { Pulse } \\
\text { response }\end{array}$ \\
\hline Cyclopropane & sinus bradycardia & $80-48$ & $\begin{array}{l}\text { atropine } \\
\quad 0.2 \mathrm{mg} \text { i.v. }\end{array}$ & 68 \\
\hline $\begin{array}{l}\text { Cyclopropane } \\
\text { Cyclopropane }\end{array}$ & $\begin{array}{l}\text { sinus bradycardia } \\
\text { sinus bradycardia }\end{array}$ & $\begin{array}{l}92-52 \\
72-48\end{array}$ & $\begin{array}{l}\text { none } \\
\text { atropine } \\
0.2 \mathrm{mg} \text { i.v. }\end{array}$ & $\begin{array}{l}56 \\
56\end{array}$ \\
\hline Cyclopropane & $\begin{array}{l}\text { atrio-ventricular } \\
\text { dissociation }\end{array}$ & $80-45$ & $\begin{array}{l}\text { atropine } \\
0.2 \mathrm{mg} \text { i.v. } \\
\text { and repeated }\end{array}$ & $\begin{array}{l}48 \\
80\end{array}$ \\
\hline Cyclopropane & $\begin{array}{l}\text { atrio-ventricular } \\
\text { dissociation }\end{array}$ & $80-60$ & none & 60 \\
\hline
\end{tabular}

Moderately heavy or heavy secretions developed at some time in the operating room or recovery room in 11 patients receiving no atropine (69 per cent), in 17 patients receiving $0.5 \mathrm{mg}$ ( 71 per cent), and in one patient receiving $1.0 \mathrm{mg}$ ( 5 per cent). These secretions were occasionally very marked and, in one instance, were thought to have caused severe laryngospasm in the recovery room.

Four patients in the study had histories of asthma and one had chronic bronchitis. There was no evidence of bronchospasm or decreased pulmonary compliance in these patients or in any of the study group.

There was no correlation between tidal volume and response to nerve stimulation. Indeed, during the administration of diethyl ether the tidal volume was frequently at, or greater than, preoperative levels, coexisting with marked depression of response to nerve stimulation. This phenomenon, however, was not noted with 
the other agents, the usual observation being decreased tidal volume persisting for some time after restoration of $4+$ tetanic response. Tidal volume in all instances eventually returned to preoperative levels.

The diminished ventilation at the end of anaesthesia and after restoration of $4+$ tetanic response was felt not to reflect a continuing muscle relaxant effect, but rather a manifestation of the residual respiratory depressant effect of the inhalation anaesthetic agent, hypocapnia secondary to hyperventilation, together with such factors as response to the presence of the endotracheal tube in the lightly anaesthetized patient.

\section{DisCUSSION}

The relaxant effect of curare is easily and quickly measured by the use of a nerve stimulator. The response to single stimulus is unreliable, since full reversal of curare may not be present when twitch response has apparently returned to base line levels. ${ }^{4}$ Several times we observed apparent complete return of single twitch response, only to find diminished response to tetanic stimulation.

Not only is return of tidal volume to preanaesthetic levels an unreliable indicator of curare reversal, 4,8 but reliance upon this method alone contains within itself the seeds of catastrophe. A dichotomy may exist between residual relaxant effect and tidal volume. The same hyperventilation that produces respiratory depression or even arrest produces an apparent reversal of curare via the same mechanism, i.e. depression of arterial $\mathrm{PCO}_{2} \cdot{ }^{10-12}$ Respiratory alkalosis consistently produces a heightening of response to nerve stimulation. Normal tetanic response with respiratory depression may be misleading if the respiratory depression is due to hypocapnia, since, as the arterial $\mathrm{PCO}_{2}$ rises to normal levels, the curare effect may return in part, thus decreasing ventilation through partial paralysis of the respiratory muscles. Continued respiratory depression, without the advantages of assisted or controlled ventilation, will lead quickly to respiratory acidosis, a situation which will enhance residual curare effect. ${ }^{13}$ Thus a vicious circle may be created in which respiratory depression leads to respiratory acidosis, leading in turn to increased relaxant effect which will in turn increase respiratory depression. The patient in the operating room whose respiratory centre is responding to painful stimuli, motion, and the general activity associated with the end of the surgical procedure may have an apparently normal tidal volume. ${ }^{14}$ However, in the recovery room, with the diminution of sensory input, tidal volume may decrease, especially if a respiratory depressant narcotic is used for pain relief. Thus the cycle of respiratory acidosis and heightened curare effect may be activated.

Ideally, the anaesthesiologist should demand a normal response to tetanic stimulation, coupled with normal arterial $\mathrm{PCO}_{2}$, or at least normal ventilation. Cumulation studies have indicated a subclinical effect of curare which may extend hours into the period after the last administration of the drug. ${ }^{8}$ For how many hours after the use of the drug its residual effect may be unmasked by respiratory acidosis is as yet conjectural. Prudence, however, demands either adequate reversal of curare at the end of anaesthesia or adequate mechanical ventilation for several hours into the postoperative period. 
Another hazard of an adequate tidal volume without adequate curare reversal is the sanguine feeling often adopted by the clinician who sees his patient breathing well and thus becomes oblivious to the fact that residual relaxant effect may limit respiratory reserve and vital capacity, to the point where clearing of secretions is impossible. Thus the stage is set for constant tidal volume, pooling of secretions, and the development of atelectasis, shunt effects, and pneumonitis. ${ }^{15,18}$

All patients in the study demonstrated residual relaxant effect at the end of anaesthesia, and only one case was discarded because of spontaneous reversion to $4+$ tetanic response. Experience, then, indicates that the average patient who has received curare leaves the operating room at least partially paralysed, unless the drug has been antagonized. ${ }^{7,8}$

Although disputed by some, ${ }^{17,18}$ the accepted mode of action for reversal of curare effect is inhibition of acetyl cholinesterase. ${ }^{7,19,20}$ Pyridostigmin has been estimated to have $1 / 8$ to $1 / 20$ the anticholinesterase activity of neostigmine. ${ }^{21,22}$ Its toxicity in a variety of animals is $1 / 5$ that of neostigmine. ${ }^{21}$ Reversal of curare by neostigmine ordinarily requires the use of 4 to $5 \mathrm{mg}$ of the drug., ${ }^{7,8}$ In our series, reversal was produced with $10 \mathrm{mg}$ of pyridostigmin in 84 per cent of our patients. Thus the anticurare potency of the drug is approximately one-half that of neostigmine.

Edrophonium has the most rapid onset of action of any commonly-used curare antagonist. ${ }^{22}$ However, its action is transient. Pyridostigmin, while slower in onset than either edrophonium or neostigmine, has a longer course of action. ${ }^{22}$

When used without concurrent atropine, the vagomimetic action of pyridostigmin has a tendency to produce troublesome arrhythmias and heavy pharyngeal and tracheal secretions. The addition of $0.5 \mathrm{mg}$ of atropine appears to afford some protection against arrhythmias, but none against secretions. Secretions could be guarded against only with the use of $1.0 \mathrm{mg}$ of atropine. However, marked, if transient, tachycardia was frequently seen at this dose level. While not troublesome in our series, this could be a problem in patients who might not tolerate it for even brief periods of time, for example patients with mitral stenosis or marked ischaemic heart disease.

Pyridostigmin bromide thus rivals neostigmine in its ability to antagonize the paralysing effect of d-tubocurarine. Unfortunately, however, both drugs share the troublesome side effects associated with vagomimetic drugs. Since the onset of action of pyridostigmin is relatively slow it might be possible to administer the drug and delay the administration of atropine, so that the effect of the two drugs would occur concurrently and the muscarinic effects would be antagonized at the very time of their occurrence. This would require very fine timing, however, and would be subject to the vagaries of individual human variation. Furthermore, the onset of action did not occur uniformly in all aspects. Changes in heart rate and rhythm preceded the development of increased secretions, and both of these preceded significant changes in the degree of neuromuscular blockade.

There was little difference in response to pyridostigmin when the anaesthetic agent was either methoxyflurane or cyclopropane. However, the restoration of normal tetanic response was markedly prolonged in the presence of diethyl ether. Perhaps this is representative of the additive effect of ether and curare in their 
action at the motor end plate, ${ }^{23}$ and the curare might be more quickly reversed if a larger dose of pyridostigmin were used initially. This difference in response also suggests that the mechanism of the muscle relaxant effect of methoxyflurane is not the same as that of diethyl ether.

\section{SUMMARY}

Pyridostigmin bromide in doses of 10 to $20 \mathrm{mg}$ is an effective antagonist of dtubocurarine when used in the presence of cyclopropane, diethyl ether, methoxyflurane, nitrous oxide, or halothane. When it is used without concurrent atropine, heavy pharyngeal and tracheal secretions are often found, and vagomimetic cardiac arrhythmias are not uncommon. Protection against secretions and vagal arrhythmias can be obtained only with the simultaneous use of $1.0 \mathrm{mg}$ of atropine sulfate. But, at this dose level, transient tachycardia may occur. Pyridostigmin, as a curare antagonist, is approximately one-half as potent as neostigmine, but it has a longer course of action. A plea is made for adequate reversal of curare or the use of postoperative respiratory assistance in all instances where curare is used.

\section{RÉSUMÉ}

Le bromure de pyridostigmine à la dose de 10 à $20 \mathrm{mg}$ est un antagoniste efficace de la d-tubocurarine, lorsqu'il est utilisé avec le cyclopropane, le diéthyl éther, le méthoxyflurane, le protoxyde d'azote ou l'halothane. Lorsqu'on l'utilise sans atropine, il se produit souvent d'abondantes sécrétions pharyngiennes et trachéales, et quelquefois des arythmies cardiaques d'origine vagale. On ne peut se protéger contre les sécrétions et les arythmies vagales qu'en utilisant simultanément $1.0 \mathrm{mg}$ de sulfate d'atropine. Mais, à cette dose il peut se produire une tachycardie passagère. Comme antagoniste du curare, la pyridostigmine est environ deux fois moins puissante que la néostigmine, mais son action est plus prolongée. On recommande fortement de renverser l'action du curare ou d'assister la respiration en période postopératoire dans tous les cas où le curare est utilisé.

\section{REFERENCES}

1. Blaschro, H.; Bulbring, E.; \& Chov, T. C. Tubocurarine Antagonism and Inhibition of Cholinesterases. Brit. J. Pharmacol, 4: 29 (1949).

2. Chase, H. F.; Bhattacharya, B. K.; \& Glassco, E. M. Curarizing and Anti-curarizing Action of a Group of Neostigmine-like Compounds. J. Pharmacol. Exper. Therap. 97: 409 (1949).

3. Brown, A. K. Pyridostigmin. Anaesthesia. 9: 92 (1954).

4. Katz, R. L. Pyridostigmin (Mestinon) as an Antagonist of d-Tubocurarine. Anesthesiology. 28: 528 (1967).

5. McNall, P. G.; Wolfson, B.; Tuazon, J. G.; \& Siken, E. S. Use of Pyridostigmin for the Reversal of Neuromuscular Blockade. Anesth. \& Analg. 48: 1026 (1969).

6. Jones, R. E.; Deutsch, S.; \& Tunndonf, H. Effects of Atropine on Cardiac Rhythm in Conscious and Anesthetized Man. Anesthesiology. 22: 67 (1961).

7. KATZ, R. L. Neuromuscular Effects of d-Tubocurarine, Edrophonium and Neostigmine in Man. Anesthesiology. 28: 327 (1967).

8. Walts, L. F. \& Dillon, J. B. D-Tubocurarine Cumulation Studies. Anesth. \& Analg. 47: 696 (1968). 
9. Brmenbaugh, P. O. \& Churchml-Davidson, H. C. Response to Tubocurarine Chloride and Its Reversal by Neostigmine Methylsulfate in Man. J.A.M.A. 203: 541 (1968).

10. Baraka, A. The Influence of Carbon Dioxide on the Neuromuscular Block Caused by Tubocurarine Chloride in the Human Subject. Brit. J. Anaesth. 36: 272 (1964).

11. Katz, R. L. \& Wolf, C. E. Neuromuscular and Electromyographic Studies in Man: Effects of Hyperventilation, Carbon Dioxide Inhalation and d-Tubocurarine. Anesthesiology. 25: 781 (1964).

12. Katz, R. L.; NGaI, S. H.; \& Papper, E. M. The Effect of Alkalosis on the Action of the Neuromuscular Blocking Agents. Anesthesiology. 24: 18 (1963).

13. Bush, G. H. \& Baraka, A. Factors Affecting the Termination of Curarization in the Human Subject. Brit. J. Anaesth. 36: 356 ( 1964).

14. Comroe, J. H. Physiology of Respiration. Chicago: Year Book Medical Publishers (1965).

15. Hammon, W. K. Respiratory Therapy. Peter Safar, ed. Philadelphia: F. A. Davis (1965).

16. Bendixen, H. H.; Egbert, L. D.; Hedley-Whyte, J.; Laver, M. B.; \& Pontoppidan, H. Respiratory Care. St. Louis: C. V. Mosby (1965).

17. Barrow, M. E. H. \& Johnson, J. K. A Study of the Anticholinesterase and Anticurare Effects of Some Cholinesterase Inhibitors. Brit. J. Anaesth. 38: 420 (1966).

18. Riken, W. F. \& Wescoe, W. C. Studies on the Inter-relationship of Certain Cholinergic Compounds, J. Pharmacol. Exper. Therap. 100: 454 (1950).

19. Hobbiger, F. The Mechanism of Anticurare Action of Certain Neostigmine Analogues. Brit. J. Pharmacol. 7: 223 (1952).

20. Smrth, C. M.; Cohen, H. L.; Pelikan, E. W.; \& Unna, K. R. Mode of Action of Antagonists to Curare. J. Pharmacol. Exper. Therap. I05: 391 (1952).

21. Randall, L. O.; Conroy, C. E.; Ferruggia, T. M.; Kappexl, B. H.; \& Knoeppel, C. R. Pharmacology of the Anticholinesterase Drugs - Mestinon, Prostigmin, Tensilon, and TEPP. Am. J. Med. 19: 673 (1955).

22. SMith, C. M.; Mead, J. C.; \& UnNa, K. R. Antagonism of Tubocurarine: III. Time Course of Action of Pyridostigmin, Neostigmine, and Edrophonium In Vivo and In Vitro. J. Pharmacol. Exper. Therap. 120: 215 (1957).

23. Price, H. L. \& Driprs, R. D. The Pharmacological Basis of Therapeutics, L. S. Goodman and A. Gilman, eds. 3rd ed. New York: The Macmillian Co. (1965). 